\title{
Tree-Assisted Therapy: Therapeutic and Societal Benefits from Purpose-Specific Technical Recreational Tree-Climbing Programs
}

\author{
John Gathright, Yozo Yamada, and Miyako Morita
}

\begin{abstract}
This article explains how program design can increase the therapeutic and societal benefits from programs focused on technical recreational tree-climbing. We compare a recreational program with a tree-assisted therapy program that includes purpose-specific therapeutic, educational, and motivation elements. We find that the additional elements included in the treeassisted therapy program were effective in enhancing the benefits from the tree-climbing activity.

Key Words. Community forests; environmental psychology; mood states; outdoor recreation; societal benefits; tree-assisted therapy; tree-climbing; urban forests.
\end{abstract}

Since its inception, technical recreational tree-climbing (TRTC) has grown rapidly in popularity. This style of tree-climbing is technical in the sense that it involves specialized equipment and techniques. It is recreational in the sense that it is designed to be safe and accessible for people of all ages and all levels of physical ability. The equipment and techniques of TRTC are different than those used by professional arborists. TRTC is slower than professional technical tree-climbing and strives to minimize harm to trees and forests. Local, national, and international organizations of TRTC enthusiasts typically espouse respect and conservation of trees and forests and strive to foster a sense of community among local tree-climbers and to make TRTC accessible and safe for beginners.

A rich literature has established that exercise and other activities in nature have restorative and therapeutic benefits (Ulrich 1981, 1983, 1984; Kaplan and Kaplan 1989; Hartig et al. 1991, 2001, 2003; Ulrich et al. 1991; Kaplan 1995; Kira 2006; Van Den Berg et al. 2007). Bodin and Hartig (2003) find that running in outdoor greenspaces reduces anxiety, depression, and anger more than running in an urban environment. Morita et al. (2007) find that hostility and depression decrease and vitality increases when walking in the forest as compared with walking in an urban environment. From a Japanese perspective, Uehara (1999a, 1999 b) finds that forest therapy can have mental and physical health benefits for participants and Park et al. (2007) find that taking in the forest atmosphere while walking and resting effectively contributed to participants' ability to relax and produced a significant positive sense of well-being. In Taiwan, Chang et al. (2007) found that wilderness environments can have restorative human well-being and psychophysiological values and benefits for Taiwanese adults

Gathright et al. (2006) find that TRTC can also have important therapeutic benefits for individuals. In addition, Gathright et al. (2007) demonstrate that tree-climbing can be socially beneficial in the sense that tree-climbing affects participants in a manner that makes them more environmentally conscious. The objective of the present article is to study how a community program of
TRTC can be designed to enhance these therapeutic and societal benefits.

In these earlier studies, tree-climbing program participants with greater understanding of and appreciation for trees and forests experienced greater therapeutic benefit from treeclimbing activities. These same participants were also more likely to be affected in ways beneficial to society. These observations suggest the following hypothesis that we test in this study: greater therapeutic and societal benefits of TRTC can be achieved by complementing tree-climbing activities with purpose-specific therapeutic, motivational, and educational elements. We find evidence in favor of this hypothesis.

We also verify the observation that greater affinity for forests explains better outcomes from participation in tree-climbing activities. The subjects in our experiment are not self-selected into the program but participate as part of employer-sponsored activity. We find that that strength of a subject's affinity for forests is an important determinant of outcomes of interest.

Our methodology also permits us to identify the benefits of the tree-climbing programs distinct from benefits derived by participants from being in the forest setting.

\section{METHODS}

\section{Experiment Design}

We tested our hypothesis by randomly assigning subjects to participate in one of two programs: tree-climbing (TC) or treeassisted therapy (TAT). Both programs were introduced to participants as tree-climbing, and the participants were not told that there were two different programs. To measure the impact of the programs on the participants, the participants completed surveys (discussed subsequently) regarding their emotions and perceptions before, during, and after their participation in one of the programs.

The two programs differed only in that the TAT program included purpose-specific therapeutic, educational, and motivational elements that were not part of the TC program. We will first describe the TC program and then we specify in what ways 
Table 1. Tree-climbing program design elements.

\begin{tabular}{lll}
\hline Elements & TC & TAT \\
\hline "Break the ice" self-introduction game & $\mathrm{X}$ & $\bigcirc$ \\
Low-impact root protection by collecting leaves & $\mathrm{X}$ & $\bigcirc$ \\
Self-introduction & $\bigcirc$ & $\mathrm{X}$ \\
5 min "act like a tree" stretch & $\mathrm{X}$ & $\bigcirc$ \\
5 min stretch & $\bigcirc$ & $\mathrm{X}$ \\
Demonstration & $\bigcirc$ & $\bigcirc$ \\
Forest appreciation & $\mathrm{X}$ & $\bigcirc$ \\
"Breathe like a tree" & $\mathrm{X}$ & $\bigcirc$ \\
Touch and Hug The Tree & $\bigcirc$ & $\bigcirc$ \\
Free tree-climbing & $\bigcirc$ & $\mathrm{X}$ \\
Treetop Relax Time & $\mathrm{X}$ & $\bigcirc$ \\
Climb down & $\bigcirc$ & $\bigcirc$ \\
"Tree and People" picture presentation & $\mathrm{X}$ & $\bigcirc$ \\
\hline
\end{tabular}

$\mathrm{TC}=$ tree-climbing; TAT $=$ tree-assisted therapy.

the TAT program was different. Table 1 compares the design elements of the two programs.

\section{Tree-Climbing Program}

The TC program was designed with the goal of providing an enjoyable outdoor experience in a relaxed and informal setting. For this program, the participants assembled in a designated climbing area where equipment was already in place (climbing ropes in the trees). The program began with a short safety and equipment explanation and 5 min of stretching and warm up, 3 min for participants to introduce themselves to the group, $5 \mathrm{~min}$ for each participant to put on the climbing gear, and a $5 \mathrm{~min}$ tree-climbing demonstration by the instructor.

The participants were then allowed to select a rope to climb and encouraged to climb to the treetop, spend some time in the tree, and then descend as they pleased. Participants were invited to observe other climbers, climb again, or talk with friends until the end of the session. The tree-climbing session was designed to be fun and enjoyable but did not include any specific therapeutic design or forest and tree education.

\section{Tree-Assisted Therapy Program}

Like the TC program, the TAT program was designed with the goal of providing an enjoyable outdoor experience in a relaxed and informal setting. The TAT program was also designed to accomplish three additional objectives. First, the program was designed to be therapeutic from a restorative and emotional well-

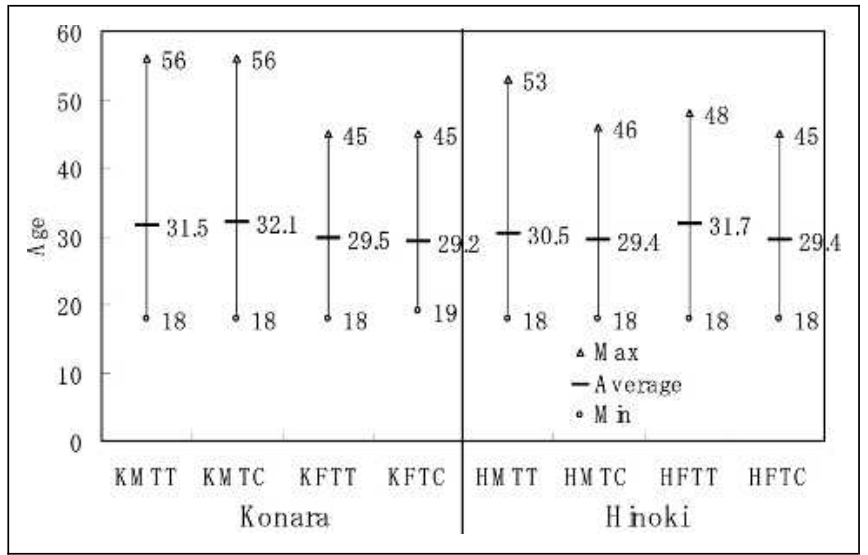

Figure 1. Mean age of each group.
Table 2. Subject groups.

\begin{tabular}{lllll}
\hline Group & Number & Species & Gender & Course \\
\hline KMTT & 26 & Konara & Male & Tree-assisted therapy \\
KMTC & 27 & Konara & Male & Tree-climbing \\
KFTT & 26 & Konara & Female & Tree-assisted therapy \\
KFTC & 27 & Konara & Female & Tree-climbing \\
HMTT & 26 & Hinoki & Male & Tree-assisted therapy \\
HMTC & 26 & Hinoki & Male & Tree-climbing \\
HFTT & 25 & Hinoki & Female & Tree-assisted therapy \\
HFTC & 25 & Hinoki & Female & Tree-climbing \\
\hline
\end{tabular}

being perspective. The second objective was educational: to increase participants' understanding of and appreciation for trees and forests. The third objective was to motivate participants to be more environmentally conscious in their behavior.

The TAT program began with a short "break the ice" game. There followed a 5 to $10 \mathrm{~min}$ tree and forest appreciation session in which the head instructor discussed the tree that was to be climbed, the forest, and forest conservation issues in Japan. Participants then collected leaves from the forest to cushion the roots from the impact of the climbing activity. Next was a brief deep-breathing exercise in which participants were to "breathe like a tree." The instructor explained that trees are the lungs of the earth, that they breathe the air that we exhale, and that we breathe the air exhaled by trees. Participants then put on treeclimbing gear and went through safety and climbing instructions. Before climbing, each participant touched the tree as a sign of respect. The instructors encouraged the climbers to spend 10 or more minutes in the treetop to observe and to reflect about nature and themselves. The participants then slowly descended as a group. The remaining $15 \mathrm{~min}$ of the TAT program included a presentation and discussion about trees overcoming natural obstacles and time for participants to share their treetop observations.

Both the TC and TAT programs took a little longer than scheduled by 5 to $10 \mathrm{~min}$.

The number of instructors, climbing height ( 8 to $11 \mathrm{~m} \mathrm{[26.4} \mathrm{to}$ $36.3 \mathrm{ft}]$ ), equipment, and procedures were exactly the same for both the TC and the TAT programs. Both programs used the same trees, only at different times. The weather and temperatures were very similar (sunny and warm) for all sessions.

\section{Setting}

The experiment was conducted in cooperation with Tree Climbing Japan (TCJ) at their location in Seto, Japan. Established in

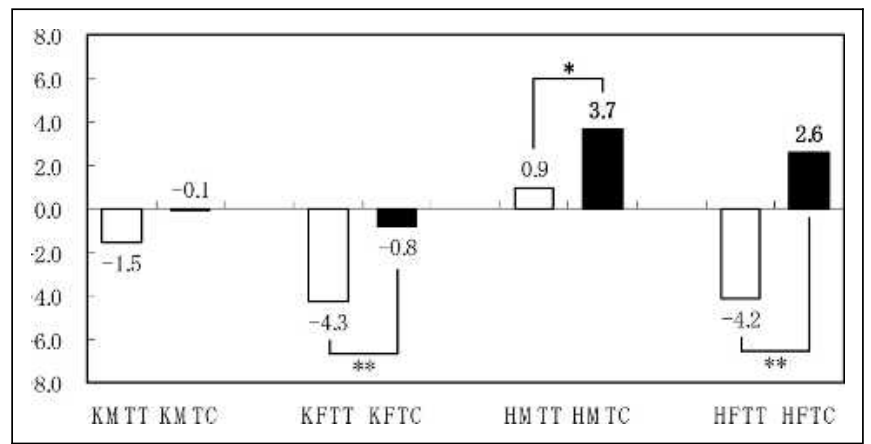

Figure 2. Differences in tension-anxiety from before and after programs. Statistical significance by the unpaired t-test ${ }^{* *} P<0.01,{ }^{*} P<0.05$. 


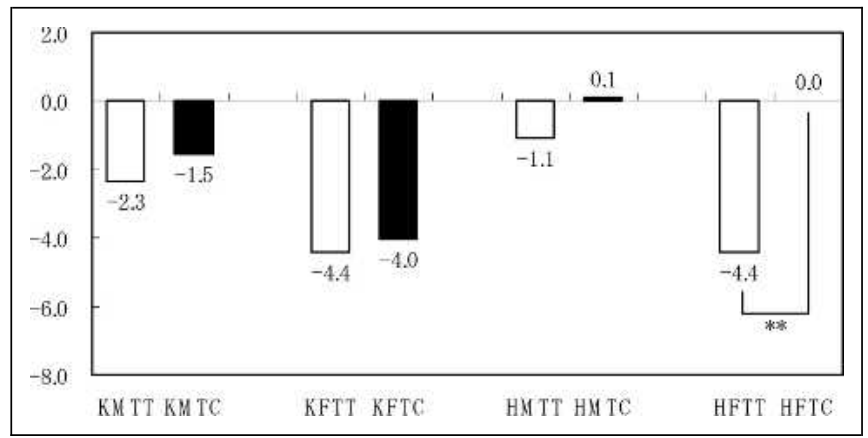

Figure 3. Differences in anger-hate from before and after programs. Statistical significance by the unpaired t-test ${ }^{* *} P<0.01,{ }^{*} P<0.05$.

2000, TCJ has assisted more than 45,000 individuals to enjoy the benefits of tree-climbing. In these 7 years, the demographics of TCJ participants have changed from only small groups with special needs to include large groups who desire a combination of therapeutic and environmental educational elements and exhilarating tree-climbing activities.

\section{Tree Species}

This study also considers the selection of species of tree to climb. In our previous research (Gathright et al. 2007) and, also in the research of Coss and Moore (2002) and Wolf (2004), it is apparent that people have definite visual and climbing tree preferences. In the current study, we explore the implications of these preferences by using both Hinoki (Cypress Chamanecyparis obtuse Sieb. et Zucc) and Konara (Quercus serrata Murry) trees.

The field used in the experiment consisted of a small grove of Hinoki trees and a grove of predominantly Konora trees. The Hinoki and Konara trees were both approximately 60 to 85 years old. The Hinoki trees were between 23 and $27 \mathrm{~m}$ (75.9 and 89.1 $\mathrm{ft}$ ) in height with a trunk diameter of 74 to $77 \mathrm{~cm}$ (29.6 to 30.8 in). The Konara trees were 18 to $21 \mathrm{~m}(59.4$ to $69.3 \mathrm{ft})$ in height with trunk width of 0.69 to $73 \mathrm{~cm}$ ( 0.28 to 29.2 in). Hinoki trees can be described as an evergreen tree with a conical shape, which reaches heights of approximately $40 \mathrm{~m}(132 \mathrm{ft})$. The dark green scale-like leaves will turn brownish in winter. The red-brown bark tends to peel and create bark dust while climbing. Hinoki trees are highly valued in Japan for their religious significance as well as for soft white wood.

Konara are deciduous trees with serrated leaves, wide open crowns, and hard, thick white bark, which is very durable. The

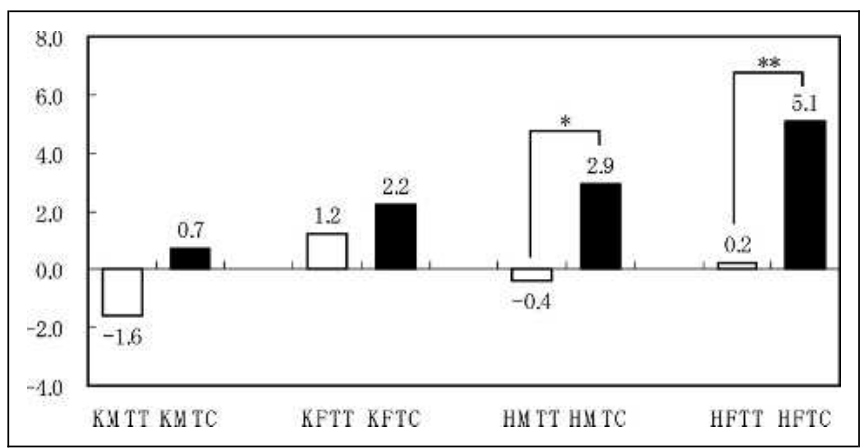

Figure 4. Differences in fatigue from before and after programs. Statistical significance by the unpaired t-test ${ }^{* *} P<0.01,{ }^{*} P<0.05$.

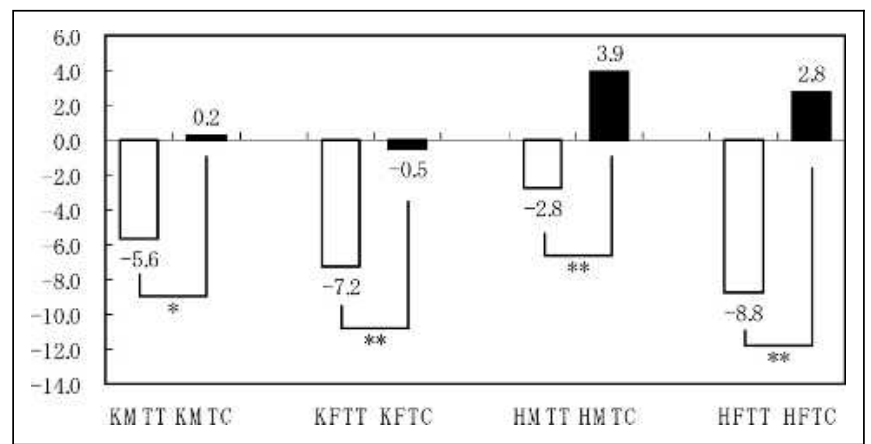

Figure 5. Differences in confusion from before and after programs. Statistical significance by the unpaired t-test ${ }^{* *} P<0.01,{ }^{*} P<0.05$.

bark rarely peels or shows evidence of wear after tree-climbing. Konara trees historically were used for making firewood and charcoal and not considered to have any particular religious value. Each group was assigned to one of two tree-climbing areas, the grove of Hinoki trees or the grove of Konara trees. Although the trees varied in height, this experiment was designed so that the rope anchors allowed for climbing zone between 8 and $11 \mathrm{~m}$ (26.4 to $36.3 \mathrm{ft})$ in both trees.

\section{Subjects}

The total number of subjects who participated in one of the two programs was 209. The assignment to groups was designed to create groups that included similar age and gender demographics as well as similar size. The mean age and lower and upper ages of participants is relatively constant for all eight groups as illustrated in Figure 1. Distribution over marital status and number of children is also relatively constant across the groups. The participants did not know with whom they would be grouped until just before the programs started. Each group participated in either a TC program or a TAT program.

Research on the therapeutic impact of outdoor activity often suffers from selection bias in that the participants are those who choose the activity. In the study of the physiological benefits of walking in the forest by Morita et al. (2007), 95\% of the participants had a previous favorable impression of walking in forests. Previous tree-climbing research studies were also conducted with subjects who had a desire to be in the forest and to participate in outdoor activities (Gathright et al. 2006, 2007).

The current study may suffer less from selection bias because the participants for both the TC program and the TAT program

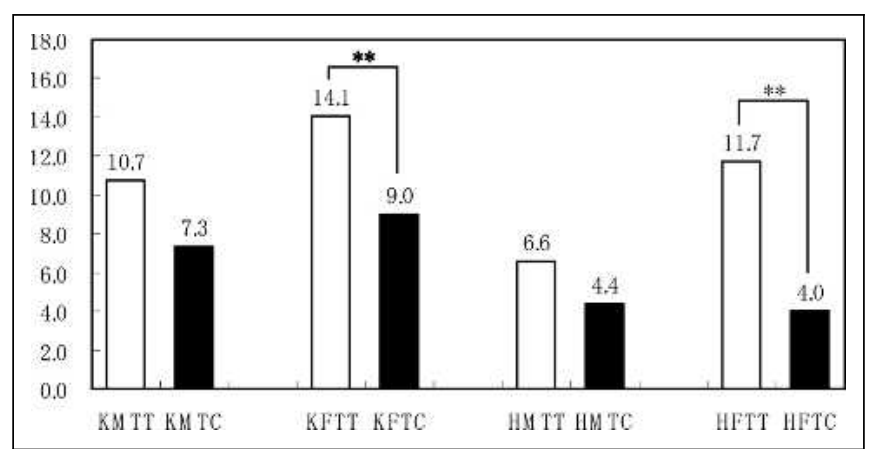

Figure 6. Differences in vitality from before and after programs. Statistical significance by the unpaired t-test ${ }^{* *} P<0.01,{ }^{*} P<0.05$. 
Table 3. $P$ values of three factors variance analysis of POMS differences between before and after the program.

\begin{tabular}{lllllll}
\hline Factors & Tension/Anger & Depression & Anger/Hate & Vitality & Fatigue & Confusion \\
\hline Konara-Hinoki & $\mathbf{0 . 0 0 1 1}$ & $\mathbf{2 . 2 7 E - 0 8}$ & $\mathbf{0 . 0 0 0 4}$ & $\mathbf{0 . 0 0 0 1}$ & 0.1101 \\
Therapy-tree-climbing & $\mathbf{1 . 8 0 E - 0 5}$ & $\mathbf{0 . 0 0 0 2}$ & $\mathbf{0 . 0 0 5 3}$ & $\mathbf{2 . 4 0 E - 0 5}$ & $\mathbf{0 . 0 0 1 1}$ & $\mathbf{5 . 1 2 E - 1 0}$ \\
Male-female & $\mathbf{0 . 0 0 4 4}$ & $\mathbf{4 . 0 2 E - 0 5}$ & $\mathbf{0 . 0 0 0 9}$ & 0.0265 & 0.0237 & 0.0610 \\
\hline
\end{tabular}

Italic bold type is $1 \%$ significant.

Italic type is $5 \%$ significant.

POMS $=$ Profile of Mood States.

were part of a company-sponsored outdoor activities agenda that included tree-climbing. The participants were all factory workers from several factories of a Japanese corporation.

\section{Questionnaires}

The questionnaires consisted of three sets of six-point polar format questions and a Profile of Mood States (POMS) evaluation of six mood states. Evaluation was conducted before, during, and after each program. Before the participants entered the treeclimbing area, they were asked to complete a POMS instrument and a questionnaire about age, gender, marital status, tree and forest appreciation, frequency of forest activities, desire to try forest activities, conservation consciousness, opinion on the environment, and other personal background information. The participants were then divided into their assigned groups for the tree-climbing activities. After they returned to the ground, a second POMS instrument was administered. After the program had completed, a final questionnaire was administered.

\section{Analysis}

For the purpose of analysis, we categorized the subjects into eight subject groups based on program, gender, and species of tree climbed (Table 2). The subject groups are unrelated to the climbing groups discussed previously. The questionnaire data were analyzed by taking the mean difference between the before and after responses on each question for each subject group.

In addition, we conducted a multifactor analysis of variance and calculated Spearman correlation coefficients as needed.

\section{RESULTS}

\section{Program Design and Therapeutic Benefits from Tree-Climbing}

We find strong evidence that program design can increase the therapeutic benefits derived from a tree-climbing program. Subject groups of participants in the TAT program exhibited

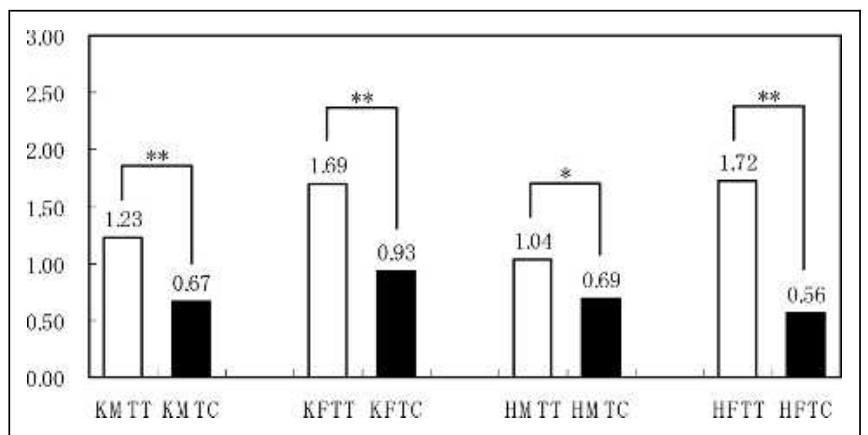

Figure 7. Differences in affinity for forests from before and after programs. Statistical significance by the unpaired t-test ${ }^{* *} P<0.01,{ }^{*} P<0.05$. changes in the mean POMS measures that were more favorable than the changes measured in comparable subject groups of TC participants. We discuss the comparison between programs for each of the POMS measures.

Participation in the TAT program is associated with a greater decrease (or smaller increase) in tension-anxiety than is participation in the TC program (Figure 2). Subject groups that climbed Konora trees in the TAT program had a greater decrease in mean measured tension-anxiety than the comparable groups of subjects who climbed the same trees in the TC program. For women who participated in the TAT program and climbed Konara trees, this larger decrease in mean measured tension-anxiety was highly statistically significant.

For men who climbed Hinoki trees as part of the TAT program, the mean measured tension-anxiety increased, but the increase was lower $(P<0.05)$ than for comparable subjects in the TC program. For women who climbed Hinoki trees as part of the TAT program, the mean measured tension-anxiety decreased, and the difference between that decrease and the increase in mean measured tension-anxiety for the comparable subject group in the TC program was highly statistically significant.

An increase in tension while climbing a Hinoki tree can possibly be explained in part by the nature of the tree. The Hinoki tree bark is easily scuffed off and the dust can be irritating for climbers below.

The mean measured anger-hate levels decreased more for subject groups of TAT participants (Figure 3). This greater decrease was highly statistically significant for women climbing Hinoki trees.

The mean of the measure of fatigue for subject groups of TC participants was higher after participating in the program (Figure 4). Subject groups of TAT participants were measured to have decreased fatigue or a smaller increase in fatigue than their comparison subject groups.

For men climbing Hinoki trees, fatigue decreased relative to before the program, and the difference between this decrease and

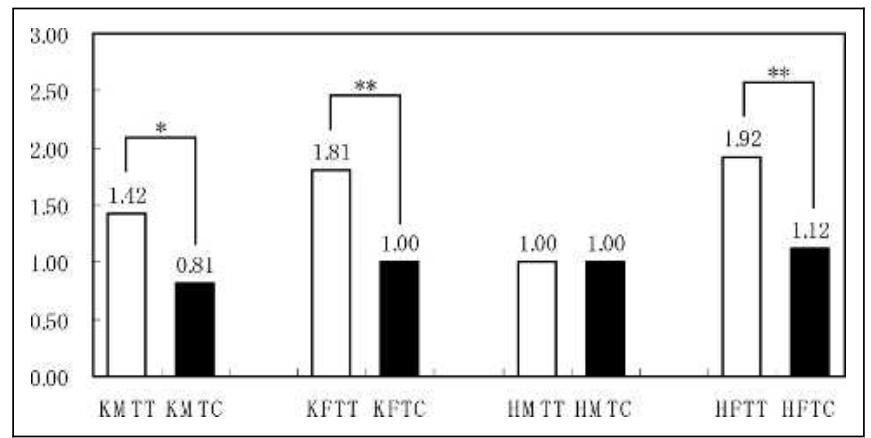

Figure 8. Differences in willingness to try new forest activities from before and after programs. Statistical significance by the unpaired t-test ${ }^{* *} P<0.01,{ }^{*} P<0.05$. 


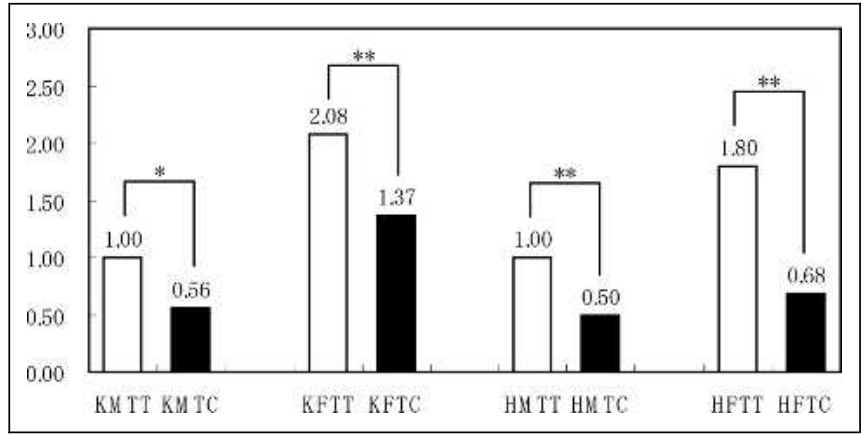

Figure 9. Differences in perception of trees as friends from before and after programs. Statistical significance by the unpaired t-test ${ }^{* *} P<0.01,{ }^{*} P<0.05$.

the increase measured for the men who climbed Hinoki trees under TC was statistically significant. The smaller increase in mean measured fatigue for women climbing Hinoki trees under TAT instead of TC was highly statistically significant.

Subject groups of TAT participants had lower mean measures of confusion after the program (Figure 5). Contrastingly, three of four TC subject groups experienced modest increases and one a very slight decrease in the mean measure of confusion. The differences in the changes between the two programs were statistically significant for all subject groups.

Confusion can be taken to mean not fully comprehending a situation or having the time to take appropriate action to deal with a negative situation. It is also derived through not having the specific emotional or physical ability to deal with a challenge or problem. The TAT program was designed to give the participants more time to appreciate trees, observe and learn about trees and the environment. It also gave them more time to think about how they would descend from the treetop. These elements may explain the greater decrease in confusion among TAT participants.

Mean measured vitality increased more for subject groups of TAT program participants than for comparable subject groups in the TC program (Figure 6). The greater increase was statistically significant for women.

The TAT program included elements such as understanding trees, breathing with trees and touching trees as well as time to simply be aware of self and space while in the tree. According to Smith and Lloyd (2006), vitality is also connected to curricular concepts of body awareness, space, time, and relationships. The

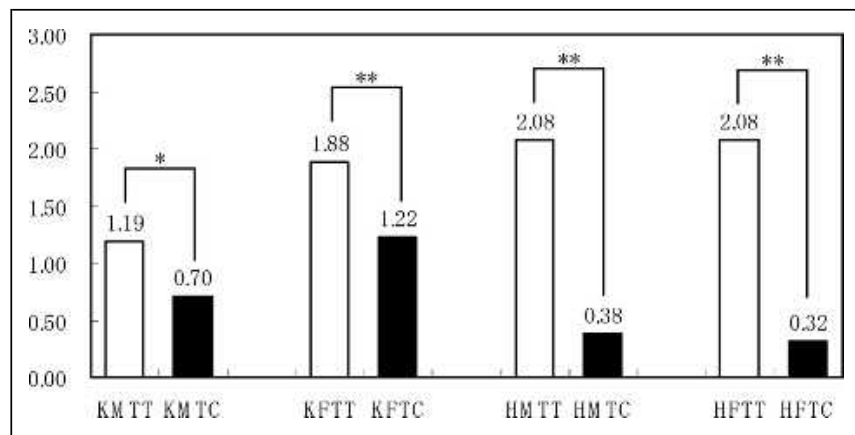

Figure 10. Differences in perception that trees are important from before and after programs. Statistical significance by the unpaired t-test ${ }^{* *} P<0.01,{ }^{*} P<0.05$.

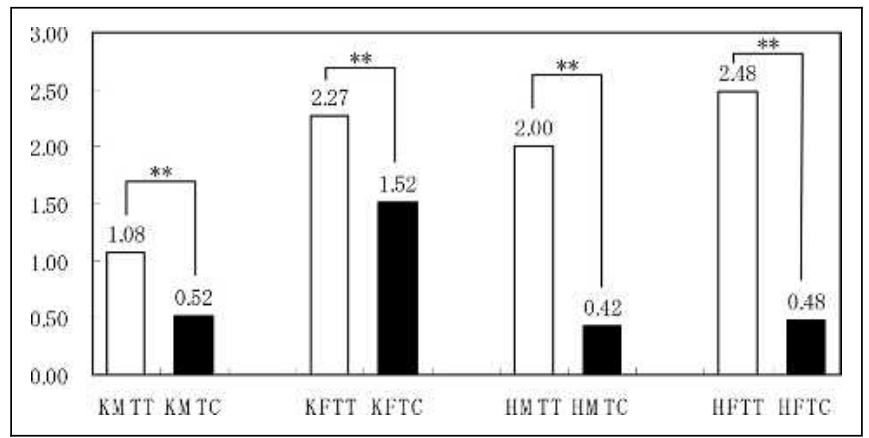

Figure 11. Differences in willingness to help forests from before and after programs. Statistical significance by the unpaired t-test ${ }^{* *} P<0.01,{ }^{*} P<0.05$.

increased vitality reported after TAT programs suggests that the affinity with trees and time allotted for treetop observation factored into the increased vitality in the TAT programs.

This evidence on the impact of program design on the mood state differences is corroborated by the results of the factor variance analysis. The results of this analysis lead to the rejection of the null hypotheses that program design is unimportant in explaining individual differences in changes to each of the POMS levels before and after program participation (Table 3). These results of the factor variance analysis are highly statistically significant.

\section{Program Design and Societal Benefits from Tree-Climbing}

Comparison of changes in the means of reports about perceptions of forests and other attitudes for participants of the two programs indicates that the TAT program affected greater improvements in these perceptions and attitudes.

Participants in TAT expressed, on average, a more dramatic increase in their affinity for forests from before the program to after the program than did the TC participants (Figure 7). The comparisons between the groups were statistically significant (highly so for men climbing Hinoki trees).

TAT participants reported a greater increase in willingness to try a new forest activity than did TC participants (Figure 8). Except for men climbing Hinoki trees, these differences in the changes were statistically significant.

TAT participants reported a greater increase in their feelings that trees are friends (Figure 9). For men climbing Konora trees, this greater increase was statistically significant, and for all the other groups, it was highly statistically significant. The concept of trees as friends may have been unfamiliar to many participants. The postprogram responses may indicate that the concept was better understood and appreciated by participants, especially by the TAT program participants.

TAT participants reported a greater increase in their feelings that trees are important (Figure 10). For men climbing Konara trees, this greater increase was statistically significant, and for all the other groups, it was highly statistically significant.

All TAT subject groups reported a greater increase in their willingness to participate in a physically demanding activity to help community forests than did their respective comparable TC subject groups (Figure 11). All of the differences in changes were highly statistically significant. 
Table 4. $P$ values of factor variance analysis of five differences from before and after programs.

\begin{tabular}{lllll}
\hline Factors & Like forests & Try act. forest & Tree friend & Tree import \\
\hline Konara-Hinoki & 0.1218 & 0.7608 & 0.0141 & 0.5166 \\
Therapy-tree-climbing & $\mathbf{7 . 0 9 E - 0 9}$ & $\mathbf{3 . 0 3 E - 0 5}$ & $\mathbf{6 . 4 2 E - 0 9}$ & $\mathbf{9 . 9 6 E - 1 8}$ \\
Male-female & 0.0103 & $\mathbf{0 . 0 0 4 2}$ & $\mathbf{2 . 5 9 E - 0 9}$ & 0.0359 \\
\hline
\end{tabular}

Italic bold type is $1 \%$ significant.

Italic type is $5 \%$ significant.

Factor variance analysis indicates that program design explains variation in the changes in perceptions about forests that come from a tree-climbing program. The explanatory power of the program design is statistically significant for each of the perceptions considered (Table 4).

\section{Program Design and Tree-Climbing Enjoyment}

Factor variance analysis indicates that program design is important in explaining the variation observed in participants' reported perceptions of the tree-climbing program (Table 5). The explanatory power of program design was highly statistically significant for each of the program perceptions measured.

As far as the question of whether tree-climbing itself was a fun activity, more TAT participants responded "very fun" than did TC participants. Among the responses from TAT participants, there were no "not very fun" responses, but there were some from TC participants. The majority of responses from TAT participants ranged from "enjoyable" to "very fun." The majority of answers for the TC program ranged from "sort of fun" to "fun."

When asked if tree-climbing was pleasant, responses of "a little unpleasant" were noticed in all four of the TC program groups, whereas there were no "a little unpleasant" responses for any of the TAT program groups. The TAT program groups were the only groups that also indicated that the tree-climbing activity was "very pleasant" with the Konara Female Tree Assisted Therapy Group (KFTT) group indicating the largest "very pleasant" response.

Concerning the satisfaction of participants with the treeclimbing activity, it is interesting to note that none of the TAT program groups responded "dissatisfied" compared with the TC groups that indicated various percentages of "dissatisfaction." On the whole, the TAT program produced the most satisfaction for all eight groups.

TAT programs produced a greater sense of accomplishment in participants compared with the TC program. A small percentage of participants in each of the four TC program groups reported that they were "not sure" if they felt any sense of accomplishment after tree-climbing. The "not sure" response was not given by any TAT program participants.

Climbing a large tree was a first-time experience for all participants in all eight groups. The greater overall impression of accomplishment after the TAT program may indicate that the sense of accomplishment was not only felt for the tree-climbing activities, but also for having gained a greater knowledge of trees and forests.

Participants in the TAT program also rated the quality and safety of the program significantly higher than TC subjects.

Given the previous results, it is surprising to note that TAT participants found tree-climbing more stressful. A possible explanation is that TAT program design included more relaxing nontree-climbing elements and that in comparison to these activities, the tree-climbing activity was a more stressful activity.

\section{Affinity for Forests and Perceptions of Tree-Climbing}

We found strong and statistically significant correlations between the affinity for forests reported by subjects before the program and many of the outcomes of interest.

Five of the eight subject groups had statistically significant correlations between affinity for forests and how fun they found tree-climbing. All of these correlations were positive (Table 6).

The findings were similar for correlation between affinity for forests and postprogram reports of satisfaction with the treeclimbing activity whether the activity was relaxing, pleasant, and whether the activity induced a sense of accomplishment.

For the reports of whether tree-climbing was scary and stressful, the correlations were statistically significant for some subject groups. All of these correlations were negative.

\section{Other Results}

We have noted that the factor variance analysis indicated that program design was important in explaining the variation in all of the outcomes of interest. The other two factors that proved important for explaining the remaining variation were tree species and gender.

Tree species was found to be an important explanatory variable for perceptions about whether tree-climbing was fun, scary, and pleasant. It was also important for explaining whether a participant's belief that trees are friends was strengthened by the program. The species of tree climbed was also an important determinant of changes in tension-anxiety, depression, angerhate, and vitality.

Table 5. $P$ values of factor variance analysis of seven perceptions from after programs.

\begin{tabular}{|c|c|c|c|c|c|c|c|}
\hline Factors & $\mathrm{TC}$ fun & TC scary & TC pleasant & TC satisfaction & TC relax & TC stress & TC acomp \\
\hline Konara-Hinoki & 0.0018 & $1.93 E-05$ & 0.0166 & 0.4120 & 0.7219 & 0.2501 & 0.2071 \\
\hline Therapy-tree-climbing & $9.82 E-07$ & $2.08 E-09$ & $2.60 E-13$ & $3.97 E-10$ & $2.61 E-11$ & $6.46 E-10$ & $1.34 E-05$ \\
\hline Male-female & 0.0523 & 0.0815 & 0.7148 & 0.0295 & 0.0001 & 0.0011 & 0.0002 \\
\hline
\end{tabular}

Italic bold type is $1 \%$ significant.

Italic type is $5 \%$ significant.

$\mathrm{TC}=$ tree-climbing; acomp $=$ accomplishment. 
Table 6. Spearman correlation coefficients between affinity for forests and perceptions of programs.

\begin{tabular}{|c|c|c|c|c|c|c|c|c|c|}
\hline Group & Visit forests & Try act. forests & TC fun & TC scary & TC pleasant & TC satisfaction & TC relax & TC stress & TC acomp \\
\hline KMTT & 0.8732 & 0.8721 & 0.6838 & -0.6294 & 0.7515 & 0.5021 & 0.4073 & -0.5662 & 0.6455 \\
\hline KMTC & 0.5907 & 0.9217 & & -0.4516 & & 0.4429 & & & 0.4520 \\
\hline KFTT & 0.6778 & 0.7280 & 0.3948 & -0.4842 & & & & & \\
\hline KFTC & 0.6716 & 0.8591 & 0.5162 & & & & 0.4042 & & \\
\hline HMTT & 0.6183 & 0.6577 & & & & & & & \\
\hline HMTC & 0.6039 & 0.6333 & & & & & & & \\
\hline HFTT & 0.8732 & 0.8721 & 0.6838 & -0.6294 & 0.7515 & 0.5021 & 0.4073 & -0.5662 & 0.6455 \\
\hline HFTC & 0.7902 & 0.8829 & 0.4143 & & & 0.4282 & & -0.4412 & \\
\hline
\end{tabular}

Italic bold type is $1 \%$ significant.

Italic type is $5 \%$ significant.

$\mathrm{TC}=$ tree-climbing; acomp $=$ accomplishment

For perceptions of the program, gender was an important explanatory factor for satisfaction with the program and perceptions about whether tree-climbing was stressful, whether it was relaxing, and whether it induced a sense of accomplishment. Gender helped explain changes in each of the perceptions and beliefs about forests. Gender was important for explaining all POMS changes except confusion.

\section{CONCLUSION}

We have tested the hypothesis that greater therapeutic and societal benefits from a community program of TRTC can be achieved by complementing tree-climbing activities with purpose-specific therapeutic, motivational, and educational elements. We have presented strong evidence in favor of this hypothesis. In particular, we have found that the participants of a tree-climbing program that was enhanced with these elements (called tree-assisted therapy) experienced greater improvement in emotional well-being and greater increase in appreciation and sympathy for the environment than did a control group in a tree-climbing program without these elements.

Our comparison of tree-assisted therapy with the control program found greater reductions in participant tension, anxiety, depression, and anger and a greater increase in participant vitality. Participants in the tree-assisted therapy program also reported greater improvement in environmentally conscious attitudes. In addition, we found that the tree-assisted therapy program provided a more enjoyable and relaxing tree-climbing experience for participants.

We have also established that participants' affinity for trees is an important explanatory variable for the outcomes of a treeclimbing program. The participants for this experiment were not self-selected, making it possible to test whether variation in affinity for trees helps explain participants' perceptions of treeclimbing programs and the extent of benefits derived from the programs. We find that those participants who have a greater affinity for trees will have a more favorable impression of treeclimbing programs, a greater desire to help forests and trees, and willingness to try other new forest activities. It is possible that the tree-assisted therapy program produces better outcomes in part because some of the extra elements included were designed to increase affinity for trees.

The results presented here provide insight for designing community tree-climbing programs. This research also establishes the merits of including purpose-specific therapeutic, educational, and motivational elements in such programs.
To our knowledge, this is the first study of the therapeutic and societal benefits of tree-climbing programs. The study builds on previous studies on the benefits of tree-climbing and on related work in forest therapy.

Our results indicate that positive health and well-being benefits from tree-climbing programs are achieved beyond those of simply being in a forest. This is because our evaluations of participants' perceptions and mood states before and after the program were conducted in the forest where the climbing took place. Our results, then, indicate that tree-climbing activities in forests would increase the positive effects of forest therapy and suggest that forest therapy and tree-climbing therapy may be complementary.

Conversely, by focusing on trees rather than on the whole forest, tree-climbing therapy is possible not only in forests, but in parks and other urban greenspaces. It provides an easily accessible activity that increases participants' appreciation of trees and their desire to help trees and forests.

The goal of this article is not to finalize a particular treeclimbing program, but to pioneer the investigation of how to design tree-climbing programs to best serve specific needs and purposes. In particular, the rehabilitative potential of treeclimbing activities for persons with disabilities or other special needs would be a valuable avenue for future research.

\section{LITERATURE CITED}

Bodin, M., and T. Hartig. 2003. Does the outdoor environment matter for psychological restoration gained through running? Psychology of Sport and Exercise 4:141-153.

Chang, C.Y., W.E. Hammitt, P. Chen, L. Machnick, and W. Su. 2007. Psychophysiological responses and restorative values of natural environments in Taiwan. Landscape and Urban Planning 85:79-84.

Coss, R.G., and M. Moore. 2002. Precocious knowledge of trees as antipredator refuge in preschool children: An examination of aesthetics, attributive judgments, and relic sexual dinichism. Ecological Psychology 14:181-222.

Gathright, J., Y. Yamada, and M. Morita. 2006. Comparison of the physiological and psychological benefits of tree and tower climbing. Urban Forestry and Urban Greening 5:141-149.

- 2007. Recreational tree climbing programs in a rural Japanese community forest: Social impacts and fun factors. Urban Forestry and Urban Greening 6:169-179.

Hartig, T., G.W. Evans, L.D. Jamer, D.S. Davis, and T. Garling. 2003. Tracking restoration in natural and urban field settings. Journal of Environmental Psychology 23:109-123. 
Hartig, T., K.G. Kaiser, and P.A. Bowler. 2001. Psychological restoration in nature as a positive motivation for ecological behavior. Environment and Behavior 3:590-607.

Hartig, T., M. Mang, and G.W. Evans. 1991. Restorative effects of natural environment experiences. Environment and Behavior 23: $3-26$.

Kaplan, R., and S. Kaplan. 1989. The Experience of Nature: A Psychological Perspective. Cambridge University Press, New York.

Kaplan, S. 1995. The restorative benefits of nature: Toward an integrative framework. Journal of Environmental Psychology 15:169-182.

Kira, K. 2006. The only place to go and be in the city: Women talk about exercise, being outdoors, and the meanings of a large urban park. Health and Place 12:631-643.

Morita, E., S. Fukuda, J. Nagano, N. Hamajima, H. Yamamoto, Y. Iwai, T. Nakashima, H. Ohira, and T. Shirakawa. 2007. Psychological effects of forest environments on healthy adults: Shinrin-yoku (forestair bathing, walking) as a possible method of stress reduction. Public Health 121:54-63.

Park, B., Y. Tsunetsugu, T. Kasetani, H. Hirano, T. Kagawa, M. Sato, and Y. Miyazaki. 2007. Physiological effects of Shinrin-Yoku (taking in the atmosphere of the forest) using salivary cortisol and cerebral activity as indicators. Journal of Physiological Anthropology 26: 123-128.

Smith, S., and R. Lloyd. 2006. Promoting vitality in health and physical education. Qualitative Health Research 16:249-267.

Uehara, I. 1999a. The possibility of forest activities in the autistic disabilities treatment by utilizing the rural forest. Leisure and Recreation Research 40:59-67 (Translated from Japanese).

. 1999b. Effects of forest recreations in the treatment of mental disabilities. Chubu Forest Research Journal 47:167-170.

. 1981. Natural versus urban scenes: Some psychophysiological effects. Environment and Behavior 13:523-556.

1983. Aesthetic and affective response to natural environment. Behavior and the Natural Environment 6:85-125.

. 1984. View through a window may influence recovery from surgery. Science 224:201-230.

Ulrich, R., R. Simons, B. Losito, E. Fiorito, M. Miles, and M. Zelson. 1991. Stress recovery during exposure to natural and urban environments. Journal of Environmental Psychology 11:201-230.

Van den Berg, A., T. Hartig, and H. Staats. 2007. Preference for nature in urbanized societies: Stress, restoration, and the pursuit of sustainability. The Journal of Social Issues 63:79-96.

Wolf, K.L. 2004. Trees and business district preferences: A case study of Athens, Georgia, U.S. Journal of Arboriculture 30:336-346.
John Gathright (corresponding author)

Nagoya University

Tree Assisted Therapy

323-4 jyokoji cho seto 4801201

Japan

info@johnsan.net

Yozo Yamada

Nagoya University

Bio Agricultural Science

323-4 jyokoji cho seto 4801201

Japan

Miyako Morito

Nagoya University

Psychology

323-4 jyokoji cho seto 4801201

Japan

Résumé. Cet article étudie comment le design planifié peut améliorer les bénéfices sociaux et thérapeutiques à partir de programmes mettant l'accent sur l'ascension récréative des arbres. Nous avons comparé un programme récréatif à un programme d'assistance-arbre thérapeutique en y incluant des objectifs spécifiques sous les aspects thérapeutiques, éducatifs et des éléments motivateurs. Nous avons découvert que les éléments additionnels qui sont inclus dans le programme d'assistancearbre thérapeutique sont efficaces pour accroître les bénéfices au niveau des activités d'ascension d'arbres.

Zusammenfassung. Diese Studie untersucht, inwieweit ein Programm-Design die therapeutischen und sozialen Vorteile eines Baumkletter-Kursangebot verbessern kann. Wir vergleichen ein Freizeitprogramm mit einem durch Bäume unterstützten Therapieprogramm, welches zweckgebundene therapeutische, erzieherische und motivierende Elemente enthält. Wir fanden heraus, dass die zusätzlichen Elemente in dem baum-unterstützten Therapie-Programm sehr effektiv die Vorteile der Kletteraktivität verstärken.

Resumen. Este reporte estudia el diseño de un programa para incrementar la terapéutica y beneficios sociales de programas encaminados a la actividad técnica de trepa a los árboles. Se diseñó una actividad recreativa con un programa de trepa a los árboles que incluye específicos propósitos terapéuticos, educativos y elementos de motivación. Se encontró que los elementos adicionales incluidos en el programa fueron efectivos para mejorar los beneficios de la actividad de trepa a los árboles. 